\title{
Computing efficient financial strategies: An extended compromise programming approach
}

\author{
M.A. Martín ${ }^{\text {a }}$, M.L. Cuadrado ${ }^{\text {a }}$, C. Romero ${ }^{\text {b. }}$ \\ a Departamento de Matemática Aplicada, Escuela Técnica Superior de ingenieros de Telecomunicaciôn, Universidad Politécnica de Madird, Madizi, Spain

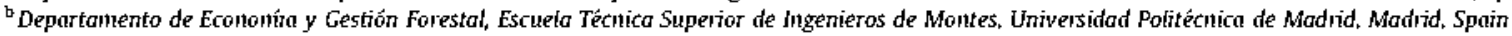

Keywords:

Compromise programming

Multiple criteria decision making

Economic optimization

Finance

\begin{abstract}
A B S T R A C T
This paper proposes a mathematical model to plan the financial strategy of a large company. The model links the philosophy of new behavioural economics with the multiple criteria decision making paradigm. Within this theoretical approach, the proposed model is supported by more realistic behavioral hypotheses. After formulating the initial multiobjective programming model, it has, due to its underlying computational difficulties, to be transformed into an easily computable extended compromise programming model. The functional and empirical potential of the model is illustrated with the help of a case study concerning a "stock market quoted" Spanish company operating in the energy sector. This paper shows how such an approach can open up new prospects for research linking economic problems with applied mathematics.
\end{abstract}

\section{Introduction}

Company profit maximization was one of the basic hypotheses of the neoclassical theory of production (Ref. [1]). In the second half of the 20th century, however, several economists challenged this hypothesis from different viewpoints. Baumol (Refs. $[2,3]$ ) was perhaps the first to call into question the classic "maximum profits" hypothesis, offering an alternative hypothesis valid for large companies (especially within an oligopolistic structure). This hypothesis, known as the "profit constrained-revenue maximization hypothesis", postulates that the behavior of certain big companies is explained by the maximization of a sales revenue objective function subject to a minimum profit constraint assuring that a "satisfactory" dividend is distributed among company stockholders. Consequently, the firm managers owe a fiduciary responsibility to the shareholders, since company investors are interested primarily in recejving as high return as possible.

Baumol's hypothesis was extended by other researchers and received sizeable empirical support (see, e.g. $[4,5]$ ). Despite this empirical support, interest in such company management theories based upon alternative premises to the classic maximization hypothesis has fallen off in the last decades. Possible explanations for this loss of interest are:

(a) A clear clash between new theories like these and the main corpus of the received economic theory. Thus, managers' goals may not necessarily be the same as those of the owners. Such ownership-management duality may lead 
self-interested managers to pursue activities that are in their own but not necessarily in the shareholders' best interest. This conflict is a potential cause of the short/long-term profitability problem.

(b) These new approaches based upon alternative behavior hypotheses require the construction of multi-criteria utility functions (or proxy functions). These functions underlie all company management theories (e.g.. [6]). For instance, non-profit or public organizations need to reflect their social interests. In this type of situation, firms tend to sacrifice monetary gains to progress in the social objective.

These two types of problems have been studied at length in the last few years. The rise of what is known as behavioral economics, where all basic economic hypotheses are tested from a psychological perspective, has opened the doors to the formulation of alternative hypotheses (e.g., Refs. [7-9]). Second, important developments in the multiple criteria decision making paradigm (MCDM) offer powerful analytical frameworks to tackle the optimization of economic problems involving several conflictive criteria (e.g., Refs. [10-12]).

This paper attempts to take a further step in this direction, that is, to formulate mathematical economic models based upon new behavioral hypotheses within a realistic MCDM framework. Moving in this direction, we propose a mathematical multiple criteria programming model valid for computing efficient strategies for large companies, inspired by the underlying theory of the behavioral economics school.

The paper is organized as follows. Section 2 defines the basic model inputs. In Section 3 a multi-objective programming model valid for computing feasible efficient strategies is presented. Section 4 discusses serious computational difficulties associated with this type of model. Consequently, the above model is transformed into an extended compromise programming model. This model is very easy to compute, since it involves solving a fewer number of linear programming problems. The proposed theory is applied to the analysis and computation of the optimal financial strategy of a large Spanish company operating in the energy sector. The last section presents the main conclusions derived from this research and indicates possible lines for further research.

\section{Definition of model inputs}

\subsection{Parameters}

$P$
$A$
$E$
$e$
$C$
$F$
$F$
$R$
$R I N$
$R E$
$G$
$T$
$i$
$K_{1}$
$K_{2}$
$\theta$
$\mu$

shareholder funds (i.e. capital and reserves)

accumulated depreciation

long-term liabilities

short-term liabilities

share capital

fixed assets

gross fixed assets

average internal rate of return over fixed assets

net returns over fixed assets

non-distributed reserves

gross profits before taxes

taxes over profits

average cost of financing the long-term liabilities

minimum acceptable level for the company's solvency (i.e. the value of the $P / E$ ratio)

minimum acceptable level for the book value of company's shares (i.e., the value of the $P / C$ ratio)

maximum average legal coefficient for the depreciation of the gross fixed assets

minimum percentage of share capital to be distributed as dividend (i.e. the Baumol's profit constraint)

\subsection{Decision variables}

$X_{1}$
$X_{2}$
$X_{3}$
$X_{4}$
$X_{5}$
$X_{6}$
$X$ annual increment of non-distributed reserves

annual increment of share capital

annual increment of accumulated depreciation

annual increment of long-term liabilities

annual increment of fixed assets

annual distributed dividend

$\left(X_{1}, X_{2}, X_{3}, X_{4}, X_{5}, X_{6}\right)=$ vector of the decision variables 


\section{A basic multi-objective model}

\subsection{Criteria}

The following would appear to be sensible criteria in the context of the long-term strategic financial planning of a large company:

1. Maximize company expansion measured by the annual increment of its permanent capital, leading to the following objective function:

$$
\operatorname{Max} f_{1}(\mathbf{X})=X_{1}+X_{2}+X_{3}+X_{4} \text {. }
$$

2. Maximize company solvency, leading to the following objective function:

$$
\operatorname{Max} f_{2}(\mathbf{X})=\frac{P+A+X_{1}+X_{2}+X_{3}}{E+X_{4}} .
$$

3. Maximize the book values of company shares, leading to the following objective function:

$$
\operatorname{Max} f_{3}(\mathbf{X})=\frac{P+A+X_{1}+X_{2}+X_{3}}{C+X_{2}} .
$$

4. Maximize the distributed dividends:

$$
\operatorname{Max} f_{4}(\mathbf{X})=X_{6} \text {. }
$$

5. Maximize the leverage measured by the difference between the average internal rate of return of the fixed assets minus the costs of financing the long-term liabilities, leading to the following objective function:

$$
\operatorname{Max} f_{5}(\mathbf{X})=R\left(F+X_{5}\right)-\mathfrak{i}\left(E+X_{4}\right) .
$$

Constraint set.

The following constraints must be met by any strategic financial plan:

1. The company solvency ratio must be greater than a minimum bound $K_{1}$, leading to the following inequality:

$$
\frac{P+A+X_{1}+X_{2}+X_{3}}{E+X_{4}} \geqslant K_{1} .
$$

2. The book or accounting value of the shares of the company must be greater than a minimum bound $K_{2}$, leading to the following inequality:

$$
\frac{P+A+X_{1}+X_{2}+X_{3}}{C+X_{2}} \geqslant K_{2}
$$

3. The internal rate of return of the fixed assets after taxes must surpass a bound RIN leading to the following inequality:

$$
\frac{(1-T)\left(G-X_{3}\right)}{F+X_{5}} \geqslant R N \text {. }
$$

4. According to Baumol's profit constraint hypothesis, the company must distribute a dividend at least equal to the $\mu$ per cent of the share capital, leading to the following inequality:

$$
X_{6} \geqslant \mu C \text {. }
$$

5. The annual cost of depreciation must be less than or equal the maximum allowed by law, leading to the following inequality:

$$
X_{3} \leqslant \theta F^{\prime} \text {. }
$$

6. For obvious reasons, the values of the decision variables cannot be negative, leading to the following set of inequalities:

$$
X \geqslant 0 \text {. }
$$

Accounting rows.

1. The annual increment of fixed assets must be covered by the annual increase of non-distributed reserves, share capita] and long-term liabilities, leading to the following identity:

$$
X_{1}+X_{2}+X_{4}-X_{5}=0 .
$$


2. The gross profits of the company after taxes must be allocated to non-distributed reserves and dividends, leading to the following identity:

$$
\left(G-X_{3}\right)-T\left(G-X_{3}\right)=X_{1}+X_{6} .
$$

This results in the following identity:

$$
X_{1}+X_{6}+(1-T) X_{3}=(1-T) G .
$$

The above criteria, constraints and accounting rows lead to the following multi-objective optimization problem:

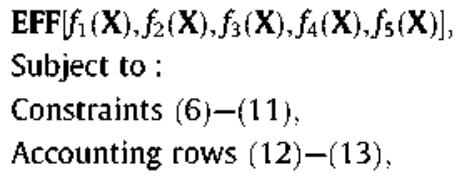

where EFF means the search for efficient maximizing solutions. Hence, solving the multi-objective programming model given by (14) will output the feasible Pareto efficient set of financial strategies, that is, feasible financial strategies where no other feasible strategy can achieve equal or better performance for all objectives and strictly better for at least one objective (see, e.g., Ref. [13]).

Even though model (14) is of moderate size, the number of extreme efficient solutions will be very large due to a rather large number of objective functions, resulting in an unmanageable amount of information (Ref. [14]). For this reason, only efficient financial strategies that represent best compromise solutions from a financial perspective, will be elicited. This task will be undertaken in the next section by formulating and solving an extended (composite) compromise programming model.

\section{An extended compromise programming model}

In order to obtain a manageable number of feasible efficient financial strategies, the multi-objective programming model given by (14) is transformed into the following extended compromise programming model (for technical details, see $[15,16])$ :

Achievement function:

MIN $\phi=(1-\lambda) D+\lambda \sum_{i=1}^{5} W_{i} \frac{f_{i}^{*}-f_{i}(X)}{f_{i}^{*}-f_{i *}}$,

Subject to :

$W_{i} \frac{f_{i}^{*}-f_{i}(X)}{f_{i}^{*}-f_{i}}-D \leqslant 0 \quad i \in\{1, \ldots, 5\}$,

Constraints $(6)-(11)$,

Accounting rows (12)-(13),

where:

$W_{i}$ relative importance or preferential weight attached to the ith objective

$f_{i}^{*} \quad$ the ideal value for the ith objective, that is, the maximum value of this objective over the constraint set, without considering the achievement of the other objectives

$f_{i *}$ the anti-ideal value for the ith objective, that is, the minimum value of this objective over the constraint set, without considering the achievement of the other objectives.

$D$ the maximum deviation or maximum degree of discrepancy

$\lambda \quad$ control parameter taking values within the closed interval $[0,1]$.

When $i=1$, model (16) maximizes the average achievement of the five financial objectives considered (i.e. second term of achievement function in (16)). On the other hand, for $\lambda=0$, the model outputs the best compromise solution minimizing the degree of discrepancy or, equivalently, maximizing the degree of balance in the achievement of the objectives (i.e. first term of the achievement function in (16)). For other values of control parameter $\lambda$ belonging to the open interval $(0,1)$, intermediate solutions, if they exist, can be obtained. Note that control parameter $\lambda$ plays the role of a "balancing factor" between "maximum average achievement" $(\lambda=1)$ and the "most balanced achievement" $(i=0)$ in this context. In short, $\lambda$ trades off efficiency ("average achievement") against equity ("most balanced achievement"). Another interesting point is that the computational burden associated with this task involves solving linear programming parametric models only (for technical details about these issues see $[17,18]$ ).

In the next section, we will apply the proposed extended compromise programming model in order to compute the best compromise financial strategies of a large Spanish company operating in the energy sector. 


\section{A case study}

The methodology proposed in Sections 3 and $\mathbf{4}$ will be used to analyse the behaviour of the Spanish firm Union Fenosa for the financial year 2007, when the Spanish energy sector was being restructured. Unión Fenosa is a group of companies focusing on the production and distribution of electrical energy and operating in several markets. Additionally, Unión Fenosa is one of the biggest Spanish companies. It is listed on the Madrid Stock Exchange and weighted in the lbex-35 index. Ibex35 is the most selective index for financial Spanish markets. From the company's balance sheet for the 2007 financial year, we selected the following data:

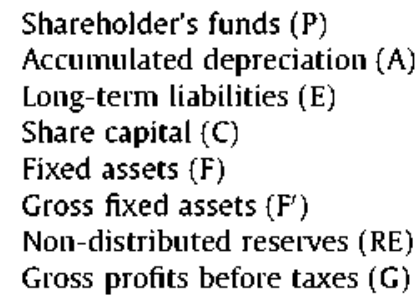

million euros
4444
7583
4087
914
14283
19016
3530
2060

(Source: Ref. [19])

The following parameter values were considered throughout the exercise:

Taxes on profits $(T)=0.30$

Average cost of financing long-term liabilities $(i)=0.07$

Baumol's constraint $(\mu)=0.30$

Average internal rate of return $(R)=0.13$

Net return over fixed assets $(\mathrm{RJN})=0.06$

Maximum average legal coefficient for depreciation $(\theta)=0.05$

Regarding the minimum acceptable levels for ratios $K_{1}$ (solvency) and $K_{2}$ (share book value), the company should at least aspire to repeat the values achieved in the previous year (i.e. 2006).

The pay-off matrix shown in Table 1 was straightforwardly obtained from the above data by separately optimizing the five objectives over the constraint set. The interpretation of the elements of this matrix is simple. Thus, the first element of the first row of the matrix represents the maximum value of $f_{1}(\mathbf{X})$ (i.e. the maximum feasible financial expansion of the company) subject to constraints (6)-(11). The other four elements of this first row represent the values of the other four objectives compatible with the maximization of objective $f_{1}(\mathbf{X})$. The other rows of the pay-off matrix have a similar meaning. By construction the elements of the main diagonal of the pay-off matrix represent the ideal vector $\left(i, . ., f_{1}^{*}, \ldots f_{5}^{*}\right)$ and the minimum value of each column of the pay-off matrix represents the anti-ideal or worst value (i.e., $f_{1 *}, \ldots, f_{5 *}$ ). The pay-off matrix has been enlarged with an additional row that shows the observed values for the five objectives considered by Unión Fenosa in 2007 (i.e. the actual financial strategies followed by the company). Noteworthy is that, as ideal and anti-ideal values often belong to the same row, the pay-off matrix obtained shows in general a high level of conflict among the set objectives. This conflict is especially relevant between the maximum financial expansion $\left(f_{1}\right)$ and maximum dividend $\left(f_{4}\right)$ objectives, and is in line with the expectations of a traditional financial analysis. Finally, another interesting point is that the actual values for Unión Fenosa in the year 2007 basically lie within the ranges defined by the difference between the ideal and the anti-ideal value for each objective.

From the above balance sheet data plus the ideal and anti-ideal values shown in the pay-off matrix, it is straightforward to implement the extended compromise programming model given by (16). The exercise was conducted by assuming that the company attaches the same importance to all five objectives (i.e. $W_{1}=\ldots W_{5}$ ). The best compromise financial strategies shown in Table 2 were output by varying the value of control parameter $i$.

Table 1

Pay-off matrix for the set five objectives considered. Bold characters denote ideal values and underlined figures anti-ideal values.

\begin{tabular}{|c|c|c|c|c|c|}
\hline & Expansion (million euros) & Solvency & Book value & Dividend (million euros) & leverage (million euros) \\
\hline Expansion $\left(f_{1}(\mathbf{X})\right)$ & 2009 & 2.94 & 13.16 & 274 & 1702 \\
\hline Solvency $\left(f_{2}(\mathbf{X})\right)$ & 1515 & 3.31 & 13.16 & 274 & 1667 \\
\hline Book value $\left(f_{3}(\mathbf{X})\right)$ & 1403 & 3.29 & 14.69 & $\underline{274}$ & 1651 \\
\hline Dividend $\left(f_{4}(X)\right)$ & $\underline{0}$ & 2.94 & 13.16 & $\overline{1442}$ & 1571 \\
\hline Leverage $\left(f_{5}(\mathbf{x})\right)$ & 1693 & 2.94 & 13.16 & 274 & 1761 \\
\hline Observed values & 1619 & 2.93 & 14.28 & 316 & 1676 \\
\hline
\end{tabular}


Table 2

Best compromise financial strategies for the set of five objectives.

\begin{tabular}{|c|c|c|c|c|c|}
\hline $\begin{array}{l}\text { Control parameter } \\
\lambda\end{array}$ & $\begin{array}{l}\text { Expansion } f_{1}(X) \text { million } \\
\text { euros }\end{array}$ & $\begin{array}{l}\text { Solvency } \\
f_{2}(\mathbf{X})\end{array}$ & Book value $f_{3}(\mathrm{X})$ & $\begin{array}{l}\text { Dividend } f_{4}(X) \text { million } \\
\text { euros }\end{array}$ & $\begin{array}{l}\text { Leverage } f_{5}(\mathbf{X}) \text { million } \\
\text { euros }\end{array}$ \\
\hline$[0,0,04]$ & 816 & 3.09 & 13.78 & 748 & 1.648 \\
\hline$(0,04,0.30)$ & 779 & 3.13 & 14,01 & 727 & 1644 \\
\hline$(0.30,0.33)$ & 1142 & 3.22 & 14.41 & 542 & 1614 \\
\hline$(0.33,1]$ & 1403 & 3.29 & 14.69 & 274 & 1651 \\
\hline
\end{tabular}

According to the theory presented in Section 4 the interpretation of the four financial strategies shown in Table 2 is rather simple. Thus, the solution corresponding to the first row of Table 2 represents the "most balanced" solution for the five objectives considered. On the other hand, the solution corresponding to the last row of Table 2 represents the "maximum average" solution, again for the five objectives considered. Finally, the other two solutions represent possible compromises among the two previous solutions, that is, compromises between the "maximum average" and the "most balanced" strategies.

Note also the close resemblance between the "maximum average" (last row of Table 2) and the financial structure actually followed by Unión Fenosa (see additional row of Table 1). In short, it is "as if" this company were looking for a best compromise strategy by additively maximizing the average achievement of the five objectives defined in the analysis undertaken.

\section{Conclusions and further research}

This paper has shown how a proper combination of behavioural economics with MCDM methods can revitalize classical financial analysis. In this way, multi-criteria mathematical programming models can play a crucjal role in building bridges between theory and practice within the behavioural economics paradigm.

Two possible extensions of this research are:

(a) To investigate the possible influence of the preferential weights $W_{i}$ in the output financial strategies. In this sense, there are two possible directions. The first would be to implement a sensitivity analysis with the preferential weights in order to check the possible robustness of the solutions. The second would be to elicit the weight values compatible with the information provided by company managers through an interactive process with these managers. To do this, a "pairwise" comparison format of the criteria considered (e.g., [20]) would appear to be a promising option. Thus, assuming "judgment reciprocity", then the managers should answer $5(5-1) / 2=10$ "pairwise" questions in our case. This would appear to be an acceptable interactive workload.

(b) To treat the preferential weights as unknowns in order to elicit the vector of weights that can provide a better approximation with respect to the actual behavior followed by the analyzed company (see [21]).

\section{Acknowledgements}

The work of Carlos Romero was supported by the "Comunidad de Madrid" (Research Grant No. Q090705-152). The comments and suggestions made by M.]. Prats, M.A. Ariño, and P. Fernández of the Spanish [ESE Business School were highly appreciated. Thanks go to Rachel Elliott for editing the English.

\section{References}

[1] S. Carlson, A Study on the Pure Theory of Production, Augustus M. Kelley Publishers, New Jersey, 1956.

[2] W. Baumol, On the theory of oligopoly. Economica 25 (1958) 187-198.

[3] W.]. Baumol, Business Behavior, Value and Growth, Harcourt Brace and World, New York, 1959. Revised ed. 1967.

[4] D.J. Smith, W.J. Boyes, D.E. Peseau, Size, Growtl, Profits and Executive Compensation in large Corporation, Macmillan, London, 1975.

[5] W.L. Beedles, A micro-econometric investigation of multi-objective firms. The Journal of Finance 32 (1977) 1217-1233.

[6] O.E. Williamson, The Economics of Discretionary Behaviour, Marginal Objectives in the Theory of the Firm, Prentice-Hall, Englewood Cliffs, New Jersey, 1964.

[7] C.F. Camerer, G. Loewenstein, M. Rabin (Eds.), Advances in Behavioral Economics, Princeton University Press, Princeton, New Jersey, 2004.

[8] P. Diamond, H. Vartiainen (Eds.), Behavioral Econonics and its Applications, Princeton University Press, Princeton, New Jersey, 2007.

[9] M.A. Ariño, J.C. Vázquez-Dodero. 5.R. Velamuri, Holistic Decision Making and Long Term Firm Performance, 55RN, abstract_id 1263786. 2008.

[10] M. Zeleny, Multiple Criteria Decision Making, McGraw Hill, New York, 1982.

[1]] C. Romero. Bi-criteria utility functions: analytical considerations and implications in the short-run labour market, European Journal of Operational Research $122(2000) 91-100$.

[12] E. Ballestero, C. Romero, Multiple Criteria Decision Making and its Application to Economic Problems, Kluwer Acadenic Publishers, Boston. Massachusetts, 1998.

[13] R.E. Steuer, Multiple Criteria Optimization: Theory, Computation and Application, John Wiley and Sons, New York, 1986. Revised ed. 1989.

[14] R.E. Steuer. Random problem generation and the computation of efficient extreme points in multiple objective linear progranming, Computational Optimization and Applications 3 (1994) 333-347. 
[15] F.J. André, C. Romero, Computing compromise solutions: on the connections between compromise programming and composite programming. Applied Mathematics and Computation 195 (2008) 1-10.

[16] M. Zeleny, Compromise programming, in: J.L. Cochrane, M. Zeleny (Eds.), Multiple Criteria Decision Making, University of South Carolina Press, Columbia, South Carolina, 1973, pp. 262-301.

[17] P.L. Yu, A class of solutions for group decision problems, Management Science 19 (1973) 936-946.

[18] P.L. Yu, Multiple Criteria Decision Making: Concepts, Techniques, and Extensions, Plenum Press, New York, 1985

[19] Orbis Company Info Global Database. 2009, Bureau van Dijk Electronic Publishing.

[20] S.l. Gass, A process for determining priorities and weights for large-scale linear goal programmes, Journal of the Operational Research Society 37 (1986) $779-785$

[21] J.M. Sumpsi, A. Amador, C. Romero, On farmers' objectives: a multicriteria approach, European Journal of Operational Research 96 (1997) 64-71. 